\title{
Impurity Removal from Carbon Saturated Liquid Iron using Lead Solvent
}

\author{
Katsunori Yamaguchi and Yoichi Takeda \\ Department of Materials Science and Technology, Faculty of Engineering, Iwate University, Morioka 020-8551, Japan
}

\begin{abstract}
A new technique for removal of tramp-elements from steel scrap is required for saving energy and protecting the environment. An extraction method using phase separation in a liquid $\mathrm{Fe}-\mathrm{Pb}-\mathrm{C}$ system was investigated at $1453 \mathrm{~K}$ to obtain fundamental information on removal of copper, tin and zinc from molten iron. A mixture of iron, lead and carbon melted in a carbon crucible separates into two phases of lead and iron containing carbon. The compositions on the miscibility gap in the $\mathrm{Fe}-\mathrm{Pb}-\mathrm{C}$ system are 95.4 mass $\% \mathrm{Fe}-4.5 \mathrm{mass} \% \mathrm{C}-0.1 \mathrm{mass} \% \mathrm{~Pb}$ and 99.9 mass \% Pb-0.1 mass\% Fe. Distribution ratios of copper, tin and zinc between the lead and the iron phases, $L_{X}=[\mathrm{mass} \% X$ in molten $\mathrm{Pb}] /$ (mass $\% X$ in molten Fe), are 2.2, 2.2 and 1.4, respectively. By adding a same amount of lead to an iron scrap, 70\% of copper and tin from the iron scrap can be eliminated. Gold, silver and palladium are enriched in the lead rich phase. However, platinum and rhodium are more distributed to the iron rich phase than to the lead phase.
\end{abstract}

(Received June 20, 2003; Accepted October 2, 2003)

Keywords: recycling of steel scrap, metal solvent, phase separation, copper removal, tin removal, precious metal, distribution ratio

\section{Introduction}

A problem causing wide concern in the recycling of steel scrap is the accumulation of tramp-elements such as copper, tin and antimony in the scrap. Copper and tin dissolved in steel tend to bring hot shortness in the hot-rolling operation of the steel-making process. Tramp elements are dissolved into molten iron, so it is difficult to remove them from steel scrap economically. A number of suggestions have been proposed and studied for removal of copper and tin from steel scrap: vacuum distillation, evaporation using ammonia, urea or chlorine, sulfide fluxes and extraction by metal solvent. ${ }^{1-14)}$ However, no economical process has been established because of their low efficiency, requirements for high cost, or high-energy consumption.

Present work is intended to establish the thermodynamic data in relation to removal of copper and tin by molten lead as a metal solvent. This method is based on the fact that affinity of copper or tin for lead is stronger than that for iron; in addition, there is a miscibility gap between molten lead and iron melt. Some investigations have addressed the removal of copper from iron using liquid lead or aluminum as metal solvents. However, they were focused on the removal of copper from solid iron. ${ }^{13,14)}$

In the present study, an extraction method using phase separation in a liquid $\mathrm{Fe}-\mathrm{Pb}-\mathrm{C}$ system has been investigated at $1453 \mathrm{~K}$ to obtain fundamental information on the removal of copper, tin and zinc from molten iron. A mixture of iron, lead and carbon was melted in a carbon crucible. We confirmed initially that clear separation of the iron and lead phases occurred as a molten state: a separate top layer of iron phase and a bottom layer of lead phase settled in the crucible according to their respective densities. The distribution ratios of copper, tin and zinc between molten lead and $\mathrm{Fe}-\mathrm{C}$ melt were measured at $1453 \mathrm{~K}$. Moreover, distribution ratios of gold, silver, palladium, platinum, and rhodium were also determined as basic data of recovery of those precious metals from steel scrap.

\section{Experimental Procedure}

The starting Fe-C alloy synthesized in a carbon crucible was 95.7 mass\% Fe-4.3 mass\% C. Along with about 0.06$0.6 \mathrm{~g}$ of tin, $0.12-0.24 \mathrm{~g}$ of zinc or $0.12 \mathrm{~g}$ of silver, gold, palladium, platinum and rhodium, about $6 \mathrm{~g}$ of lead or $\mathrm{Pb}-\mathrm{Cu}$ alloy (1-80 mass\% Cu) and an equal amount of the Fe-C alloy were put in a carbon crucible with an inner diameter of $22 \mathrm{~mm}$ and height of $100 \mathrm{~mm}$. The sample was heated at $1453 \mathrm{~K}$ at which both iron and lead concentrated phases were melted. After heating for $3.6 \mathrm{ks}$, the sample was taken out of the furnace and quenched in an argon atmosphere. The appearance of the phase separation was observed, then samples of iron and lead phases were cut out for chemical analysis. Carbon content in the iron and lead phases was analyzed by the infrared light absorption method. The contents of $\mathrm{Cu}, \mathrm{Fe}, \mathrm{Pb}, \mathrm{Sn}, \mathrm{Zn}$ and $\mathrm{Ag}$ in the alloy were determined by the atomic absorption spectroscopy. Au, Pd, Pt and $\mathrm{Rh}$ in each phase were also analyzed by the ICP atomic emission spectrometry.

\section{Results and Discussion}

\subsection{Phase separation of the Fe-Pb-C system}

Figure 1 shows a cross section of the two phases separation in the carbon saturated $\mathrm{Fe}-\mathrm{Pb}-\mathrm{C}$ system at $1453 \mathrm{~K}$. The two phases, iron rich phase of top layer and lead rich phase of bottom layer, are clearly separated in crucible. Composition of iron rich and lead rich phases are 95.4 mass $\% \mathrm{Fe}-$ 4.5 mass \% C- 0.1 mass\% $\mathrm{Pb}$ and 99.9 mass\% $\mathrm{Pb}-0.1$ mass\% $\mathrm{Fe}$, respectively. The lead content of the iron rich phase for the $\mathrm{Fe}-\mathrm{Pb}-\mathrm{C}$ ternary system determined in this study is 0.1 mass $\%$, which is lower than the Fe-Pb binary system. ${ }^{15)}$ Addition of carbon widens the miscibility gap slightly.

\subsection{Solubility of copper and carbon in iron rich phase}

Solubility changes of copper and carbon in the iron rich phase were determined in relation to the copper content in the lead rich phase. In Figs. 2 and 3 (mass $\% X$ ) and [mass\% X] are mass percentage of $X$ in the iron and lead rich phases, respectively. As shown in Fig. 2, the copper solubility in the 


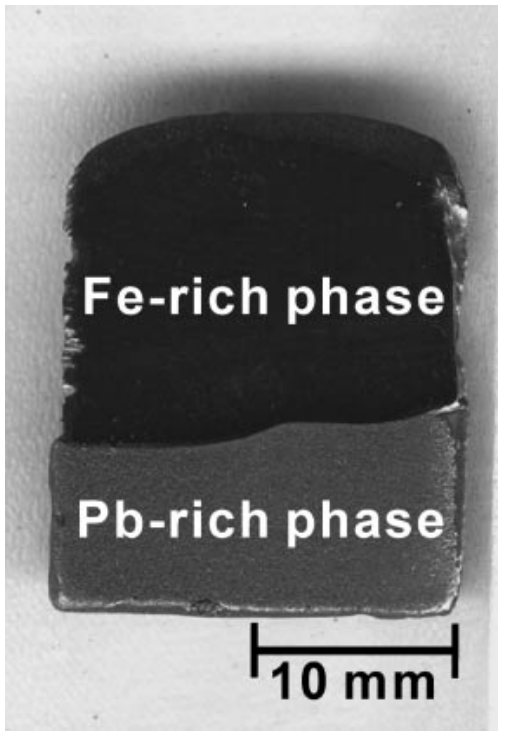

Fig. 1 View of the two phases in $\mathrm{Fe}-\mathrm{Pb}-\mathrm{C}$ system at $1453 \mathrm{~K}$. (Fe-rich phase: 95.4 mass $\%$ Fe- 4.5 mass $\%$ C- 0.1 mass $\% \mathrm{~Pb}$, $\mathrm{Pb}$-rich phase: 99.9 mass $\% \mathrm{~Pb}-0.1$ mass $\% \mathrm{Fe})$.

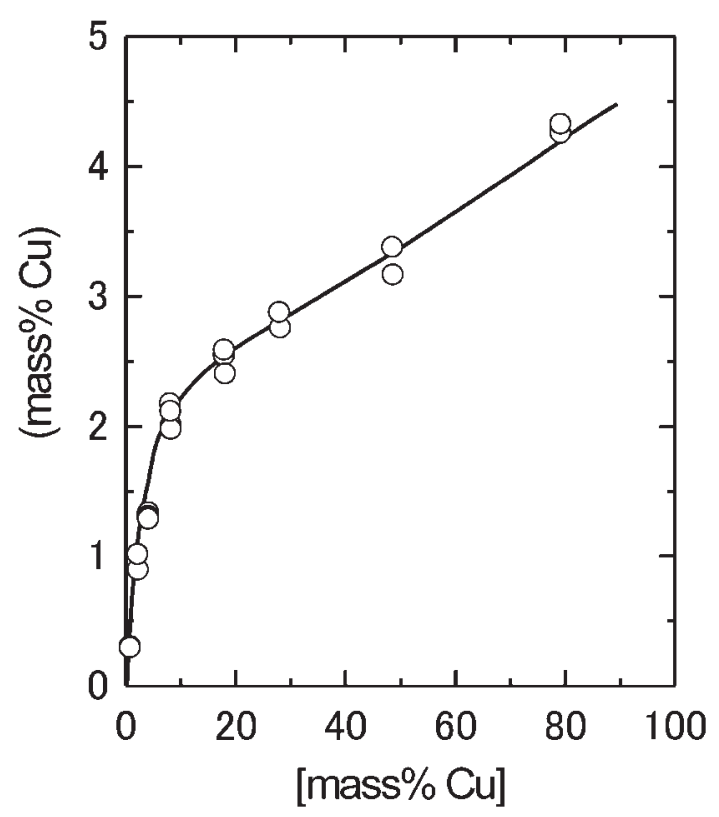

Fig. 2 Solubility of copper in Fe-rich phase against copper content in $\mathrm{Pb}$ rich phase at $1453 \mathrm{~K}$.

iron rich phase increases drastically in the region of copper content in the lead rich phase up to about 10 mass $\% \mathrm{Cu}$ and gradually above this content with increasing copper content. It is shown in Fig. 3 that the carbon solubility in the iron rich phase decreases remarkably with increasing copper content in the lead rich phase, approaching the minimum at about 35 mass $\% \mathrm{Cu}$ and then increases in the region of higher copper content.

\subsection{Distribution ratios of copper, tin and zinc}

The ability of a lead solvent to extract copper, tin and zinc from iron can be evaluated by the distribution ratio, $L_{X}{ }^{\mathrm{Pb} / \mathrm{Fe}}$, defined as follows:

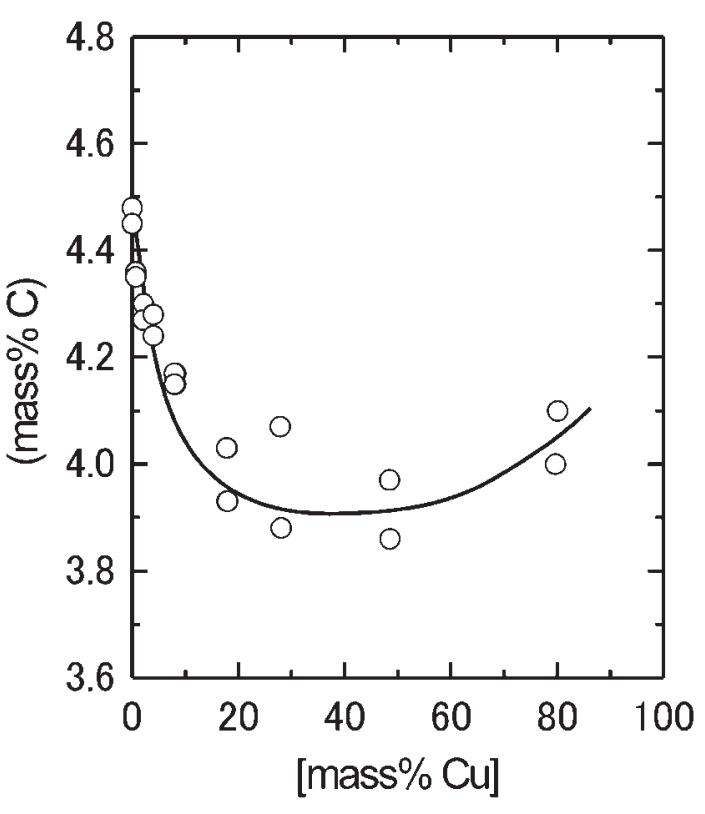

Fig. 3 Solubility of carbon in Fe-rich phase against copper content in $\mathrm{Pb}$ rich phase at $1453 \mathrm{~K}$.

$$
L_{X}{ }^{\mathrm{Pb} / \mathrm{Fe}}=[\operatorname{mass} \% X] /(\operatorname{mass} \% X) .
$$

Here $[\operatorname{mass} \% X]$ and $(\operatorname{mass} \% X)$ are mass percentages of $X$ in lead-phase and carbon-saturated iron rich phase, respectively.

The distribution ratio of $L_{\mathrm{Cu}} \mathrm{Pb} / \mathrm{Fe}$ at $1453 \mathrm{~K}$ is shown in Fig. 4 in relation to mass $\% \mathrm{Cu}$ of the lead rich phase. The value of the $L_{\mathrm{Cu}} \mathrm{Pb} / \mathrm{Fe}$ of less than about 2 mass $\% \mathrm{Cu}$ in the lead rich phase is 2.16. This value is higher than that of the $\mathrm{Fe}-\mathrm{Pb}$ binary system at $1873 \mathrm{~K}$ reported by Langenberg. ${ }^{16)}$ Addition of carbon to the $\mathrm{Fe}-\mathrm{Pb}$ system tends to slightly increase the distribution ration of copper. Above 2 mass $\% \mathrm{Cu}$ of the lead rich phase, $L_{\mathrm{Cu}} \mathrm{Pb} / \mathrm{Fe}$ increases with increasing copper content of the lead rich phase. For scrap iron initially containing about 1 mass $\% \mathrm{Cu}$, it is confirmed that the copper

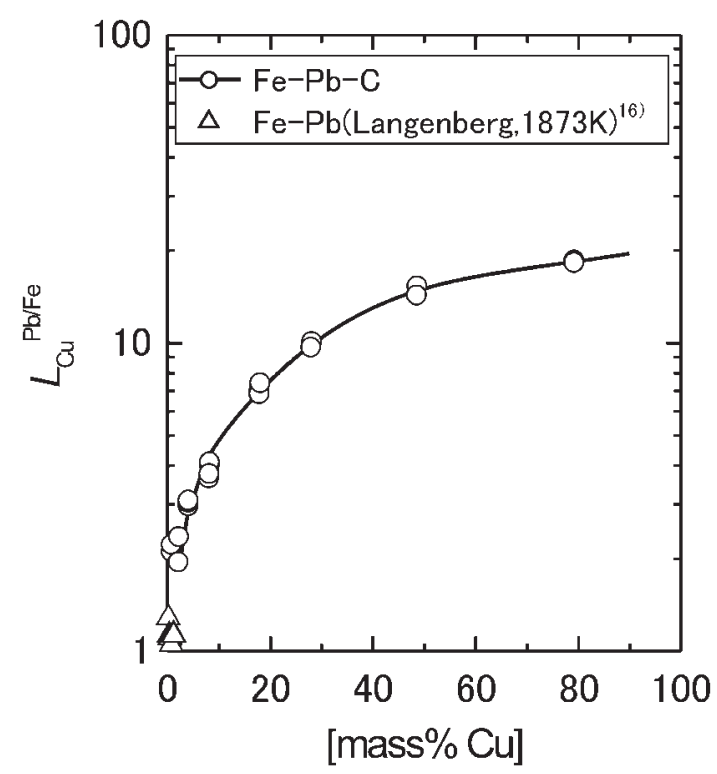

Fig. 4 Distribution ratio of copper between $\mathrm{Pb}$-rich phase and Fe-rich phase at $1453 \mathrm{~K}$. 


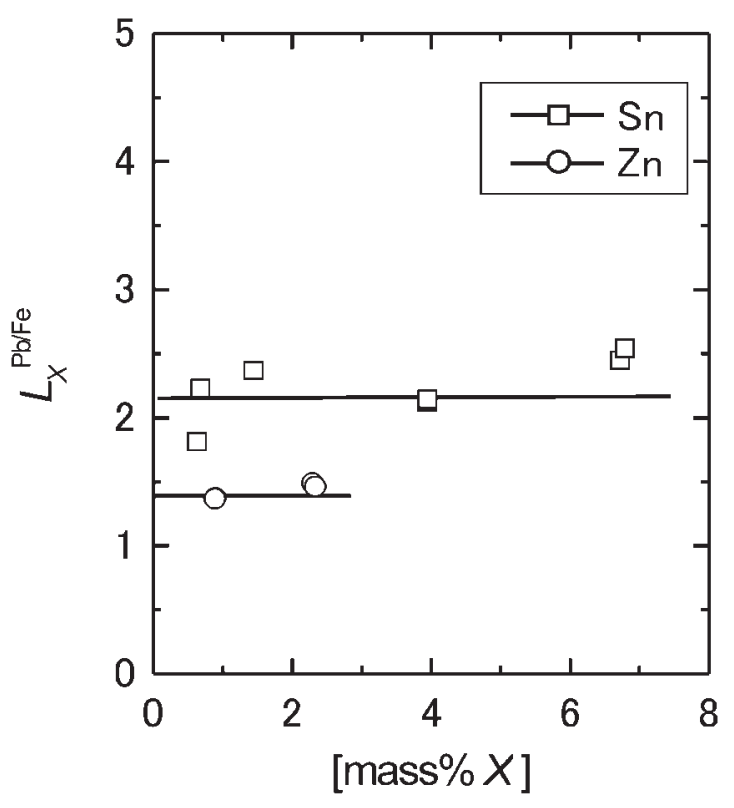

Fig. 5 Distribution ratios of tin and zinc between $\mathrm{Pb}$-rich phase and Fe-rich phase at $1453 \mathrm{~K}$.

content in the molten iron can be reduced to about one-third with the extraction method using phase separation in the liquid $\mathrm{Fe}-\mathrm{Pb}-\mathrm{C}$ system.

The distribution ratios of tin and zinc between the lead rich and the carbon saturated iron rich phases were determined at $1453 \mathrm{~K}$. The relations between $L_{X}{ }^{\mathrm{Pb} / \mathrm{Fe}}$ and contents of tin and zinc in the lead rich phase are shown in Fig. 5. The effects of tin or zinc content on $L_{X} \mathrm{~Pb} / \mathrm{Fe}$ are very small. Therefore, $L_{X} \mathrm{~Pb} / \mathrm{Fe}$ displays constant values in the experimental composition ranges. Distribution ratios of tin and zinc are 2.24 and 1.42 , respectively. Tin content in the molten iron can be reduced to about one-third by this solvent extraction.

\subsection{Removals of copper, tin and zinc}

Copper and tin distribution ratios between lead rich and the carbon saturated iron rich phases obtained in this study may seem insufficient to remove them from iron in a single operation. Techniques of a repetition or a counter flow may be effective for improving the efficiency of copper and tin removals. Extraction of copper and tin from molten iron by a lead solvent is conducted through several stages.

Based on the mass-balance relations and distribution ratios determined in this study, contents of copper, tin and zinc in molten iron using plural repetition stages are given as

$$
\begin{aligned}
(\operatorname{mass} \% \mathrm{Cu})_{n} & =(\operatorname{mass} \% \mathrm{Cu})_{n-1} \times\left[1-\left(\frac{216 R}{100+216 R}\right)\right] \\
(\operatorname{mass} \% \mathrm{Sn})_{n} & =(\operatorname{mass} \% \mathrm{Sn})_{n-1} \times\left[1-\left(\frac{224 R}{100+224 R}\right)\right] \\
(\operatorname{mass} \% \mathrm{Zn})_{n} & =(\operatorname{mass} \% \mathrm{Zn})_{n-1} \times\left[1-\left(\frac{142 R}{100+142 R}\right)\right]
\end{aligned}
$$

and

$$
R=w_{\mathrm{Pb}} / w_{\mathrm{Fe}}
$$

where $(\operatorname{mass} \% X)_{n},(\operatorname{mass} \% X)_{n-1}$ represent mass percen-

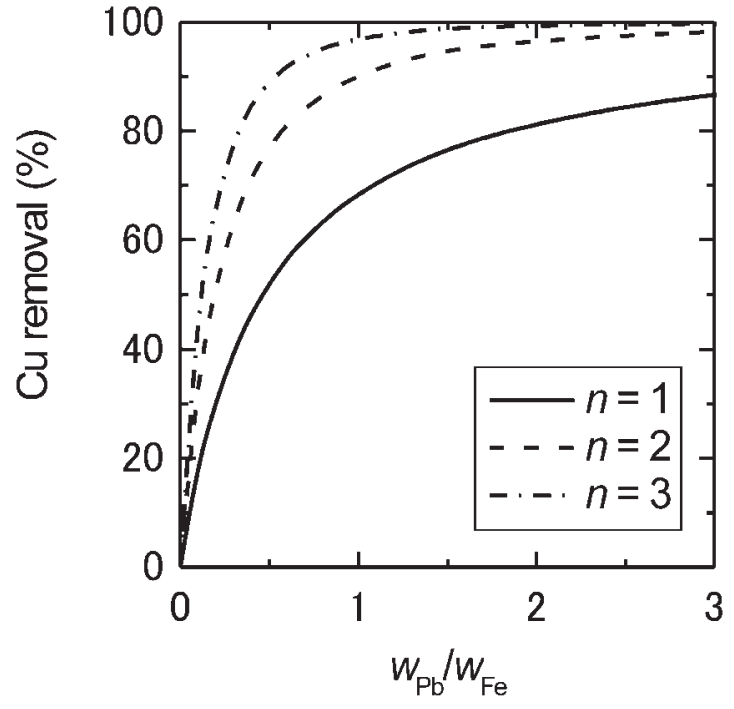

Fig. 6 Copper removal against weight ratio of lead to iron.

tages of the component $X(X=\mathrm{Cu}, \mathrm{Sn}, \mathrm{Zn})$ in the molten iron at $n$th and $(n-1)$ th stages, respectively. The $w_{\mathrm{Pb}}$ and $w_{\mathrm{Fe}}$ are weights of lead and iron.

Figure 6 shows copper removal against the weight ratio of the lead to the iron, where $n$ is the number of the extraction stage. When weights of the lead and iron are the same, copper removal is about $68 \%$ with a single treatment. On the other hand, the value of removal after two stages of copper extraction is about 90\%; after three stages, it is estimated to be about $96 \%$. Tin removal against the weight ratio of the lead to iron is shown in Fig. 7, where $n$ is the number of the extraction stage. By adding a same amount of lead to an iron, $69 \%$ of tin can be eliminated from the iron. Tin removal is about $90 \%$ after two stages of extraction; it is about $97 \%$ after three stages.

When the impurity removal of iron scrap by applying phase separation between iron and lead in the $\mathrm{Fe}-\mathrm{Pb}-\mathrm{C}$ system is carried out, large amounts of the iron containing 0.1 mass $\% \quad \mathrm{~Pb}$ and the lead dissolving impurities are produced. The copper and zinc in molten lead are separated from the lead above melting point of lead by cooling. The tin

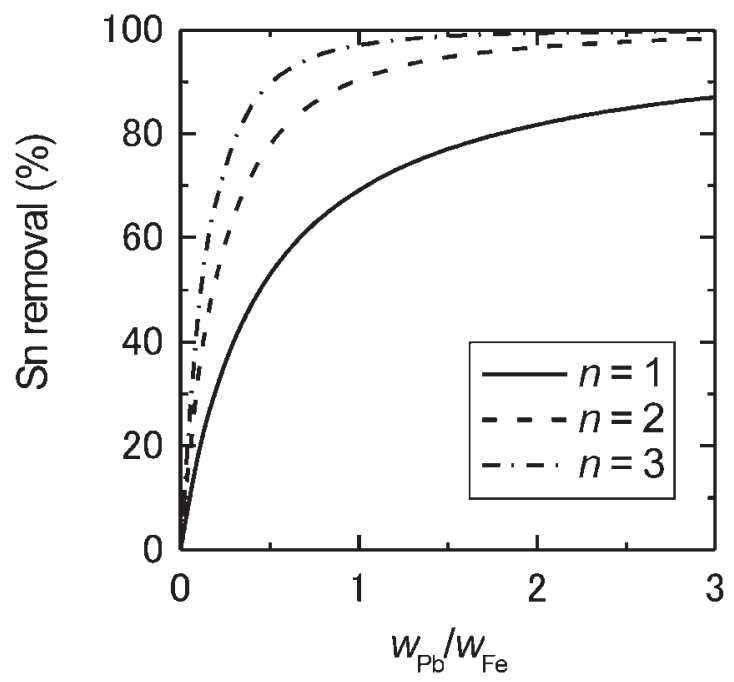

Fig. 7 Tin removal against weight ratio of lead to iron. 
Table 1 Distribution ratios of $X(X: \mathrm{Cu}, \mathrm{Sn}, \mathrm{Zn}, \mathrm{Ag}, \mathrm{Au}, \mathrm{Pd}, \mathrm{Pt}, \mathrm{Rh})$ between $\mathrm{Pb}$-rich phase and Fe-rich phase at $1453 \mathrm{~K}$.

\begin{tabular}{ccccccccc}
\hline Element & $\mathrm{Cu}$ & $\mathrm{Sn}$ & $\mathrm{Zn}$ & $\mathrm{Ag}$ & $\mathrm{Au}$ & $\mathrm{Pd}$ & $\mathrm{Pt}$ & $\mathrm{Rh}$ \\
\hline$L_{X}{ }^{\mathrm{Pb} / \mathrm{Fe}}$ & 2.16 & 2.24 & 1.42 & 230 & 16 & 23 & 0.054 & 0.069 \\
\hline
\end{tabular}

in the liquid lead can also be removed from the lead by Harris process using $\mathrm{NaOH}$ or $\mathrm{NaNO}_{3}$. However, removal of lead from the iron will be a next focus.

\subsection{Distribution ratios of precious metals}

Distribution ratios $L_{X} \mathrm{~Pb} / \mathrm{Fe}$ as defined by eq. (1), of precious metals between the lead and iron rich phases are determined as basic data for recovery of precious metal from scrap. Table 1 lists distribution ratios of silver, gold, palladium, platinum, and rhodium along with data for copper, tin and zinc. We can recognize that silver, gold and palladium are enriched in the lead rich phase, on the contrary, platinum and rhodium are enriched in the iron rich phase.

Recovery of precious metals from molten iron using lead solvent extraction was estimated based on the distribution ratios determined in this study. Figure 8 shows the recovery of precious metals, where $n$ is the number of extraction stages. When a same amount of lead is added to an iron, recovery of silver, gold and palladium are about $100 \%, 95 \%$ and $96 \%$, respectively. Silver, gold and palladium can recover efficiently into the lead phases. However, platinum and rhodium are hardly transferred to the lead rich phase.

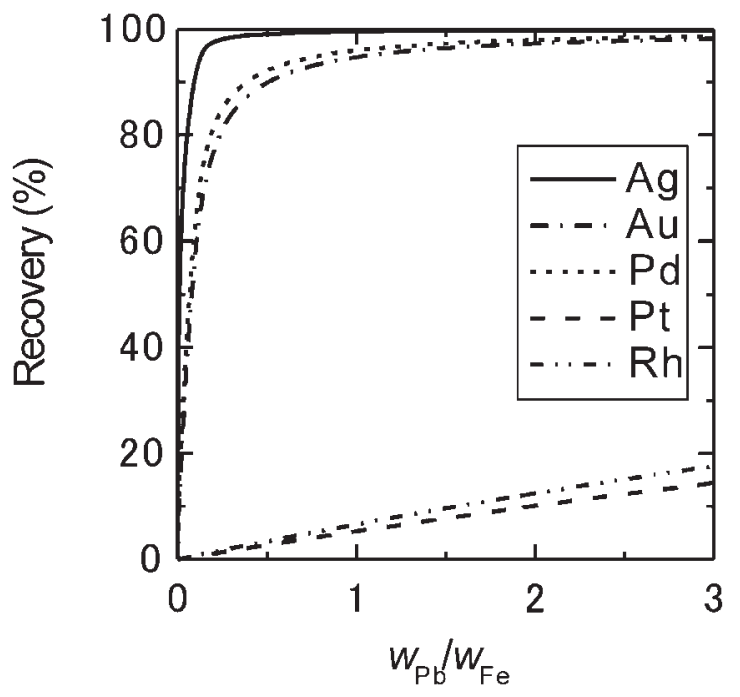

Fig. 8 Recovery of precious metals against weight ratio of lead to iron.

\section{Conclusion}

Some fundamental experiments on solvent extraction were conducted using liquid lead as a solvent to remove copper, tin and zinc from carbon saturated molten iron. Iron rich 95.4 mass \% Fe-4.5 mass\% C-0.1 mass\% $\mathrm{Pb}$ alloy forms a clearly separated top layer and lead rich 99.9 mass $\% \mathrm{~Pb}-$ $0.1 \mathrm{mass} \% \mathrm{Fe}$ alloy forms a bottom layer in a carbon crucible at $1453 \mathrm{~K}$. Distribution ratios of copper, tin and zinc between the lead and the iron phases are 2.16, 2.24 and 1.42, respectively. Copper and tin are enriched in the lead rich phase. About $70 \%$ of copper and tin can be eliminated from scrap iron by adding a same amount of lead to an iron scrap. Gold, silver and palladium are enriched in the lead rich phase; in contrast, platinum and rhodium are more distributed to the iron rich phase than to the lead phase.

\section{Acknowledgments}

The authors would like to express their gratitude to Prof. K. Itagaki of Tohoku University for his helpful suggestions and also to Kosaka Smelting \& Refining Co., Ltd. for chemical analysis of the precious. This work was partly suported by the Regional Science Promotion (RSP) of Iwate.

\section{REFERENCES}

1) I. Jimbo, M. S. Sulsky and R. J. Fruehan: Iron Steelmaker 15 (1988) 2023.

2) C. Wang, T. Nagasaka, M. Hino and S. Ban-ya: ISIJ Int. 31 (1991) 1300-1308.

3) C. Wang, T. Nagasaka, M. Hino and S. Ban-ya: ISIJ Int. 31 (1991) 1309-1315.

4) K. Ono, E. Ichise, R.O. Suzuki, and T. Hidani: Steel Res. 66 (1995) 372-376.

5) K. Matsumaru, M. Susa and K. Nagata: Tetsu-to-Hagane 86 (1996) 1-6.

6) M. Sasabe, E. Harada and S. Yamashita: Tetsu-to-Hagane 86 (1996) 31-38.

7) T. Maruyama, H. G. Katayama, T. Momono, Y. Tayu and T. Takeuchi: Tetsu-to-Hagane 84 (1997) 1-6.

8) R. Shimpo, Y. Fukaya, T. Ishikawa and O. Ogawa: Metall. Mater. Trans. B 28B (1997) 1029-1037.

9) T. Nagasaka and M. Hino: Shigen-to-Sozai 113 (1997) 1101-1105.

10) T. Nishi, S. Fukagawa, K. Shinme and T. Matsuo: ISIJ Int. 39 (1999) 905-912.

11) T. Matsuo: Tetsu-to-Hagane 86 (2000) 33-39.

12) L. Savov and D. Janke: ISIJ Int. 40 (2000) 95-104.

13) M. Iwase and K. Tokinori: Steel Res. 62 (1991) 235-239.

14) R. Shimpo and O. Ogawa: Trans. Mater. Res. Soc. JAPAN 24 (1999) 337-340.

15) Y. A. Chang, J. P. Neumann, A. Mikula and D. Goldberg: INCRA Monograph, The Metallurgy of Copper. Series VI. (International Copper Research Association, Inc., 1979) p. 68.

16) F. C. Langenberg: J. o. M. (1956) 1024-1025. 